\title{
Rice yellow stunt rhabdovirus Protein 6 Suppresses Systemic RNA Silencing by Blocking RDR6-Mediated Secondary siRNA Synthesis
}

\author{
Hongyan Guo,, ${ }^{1,2,3}$ Xiaoguang Song, ${ }^{1,2,3}$ Chuanmiao Xie, ${ }^{1,2,3}$ Yan Huo, ${ }^{1,2,3}$ Fujie Zhang, ${ }^{1,2,3}$ Xiaoying Chen, \\ Yunfeng Geng, ${ }^{1,2}$ and Rongxiang Fang ${ }^{1,2}$ \\ ${ }^{1}$ State Key Laboratory of Plant Genomics, Institute of Microbiology, Chinese Academy of Sciences, Beijing 100101, China; \\ ${ }^{2}$ National Plant Gene Research Center, Beijing 100101, China; ${ }^{3}$ University of Chinese Academy of Sciences, Beijing \\ 100049, China
}

Submitted 4 February 2013. Accepted 23 April 2013.

\begin{abstract}
The P6 protein of Rice yellow stunt rhabdovirus (RYSV) is a virion structural protein that can be phosphorylated in vitro. However its exact function remains elusive. We found that P6 enhanced the virulence of Potato virus $X$ (PVX) in Nicotiana benthamiana and $N$. tabacum plants, suggesting that it might function as a suppressor of RNA silencing. We examined the mechanism of P6-mediated silencing suppression by transiently expressing $\mathrm{P} 6$ in both $N$. benthamiana leaves and rice protoplasts. Our results showed that P6 could repress the production of secondary siRNAs and inhibit systemic green fluorescent protein RNA silencing but did not interfere with local RNA silencing in $N$. benthamiana plants or in rice protoplasts. Intriguingly, P6 and RDR6 had overlapping subcellular localization and P6 bound both rice and Arabidopsis RDR6 in vivo. Furthermore, transgenic rice plants expressing P6 showed enhanced susceptibility to infection by Rice stripe virus. Hence, we propose that $P 6$ is part of the RYSV's counter-defense machinery against the plant RNA silencing system and plays a role mainly in affecting RDR6-mediated secondary siRNA synthesis. Our work provides a new perspective on how a plant-infecting nucleorhabdovirus may counteract host RNA silencing-mediated antiviral defense.
\end{abstract}

In plants, RNA silencing plays prominent roles in defense against invading nucleic acids such as viruses and transposons (Csorba et al. 2009). Briefly, antiviral silencing is initiated when viral double-stranded RNAs (dsRNAs) or highly structured regions of single-stranded viral RNAs are processed into 21- to 24-nucleotide (nt) small interfering RNA (vsiRNA) duplexes by dsRNA-specific RNaseIII-type Dicer-like (DCL) enzymes (Ding and Voinnet 2007). One strand of the vsiRNA duplex is then incorporated into the RNA-induced silencing complex (RISC) containing the core component Argonaute (AGO) proteins to guide the degradation of complementary viral RNA targets (Pantaleo et al. 2007). Recently published data

Corresponding authors: R. Fang; Telephone and Fax: +86-10 64858245; E-mail: fangrx@im.ac.cn; and Y. Geng. Telephone: +86-10 64861838; Fax: +86-10 64858245; E-mail: yfgeng@126.com

* The $\boldsymbol{e}$-Xtra logo stands for "electronic extra" and indicates that two supplementary figures are published online and that Figures 1 and 4 appear in color online.

C 2013 The American Phytopathological Society demonstrated that, in plants, viral secondary siRNAs, derived from dicing of secondary dsRNA synthesized by the host RNA-dependent RNA polymerase (RDR)1 or RDR6, are also necessary for successful resistance to virus infection $(\mathrm{Qu}$ et al. 2005; Yang et al. 2004). Finally, the amplified silencing signal can spread locally, between neighboring cells through plasmodesmata, and systemically, via the vascular system, persisting for a long time (Melnyk et al. 2011).

Viruses have evolved counterdefense mechanisms to thwart the host silencing system. In plants, many, if not all, viruses with positive- or negative-sense RNA or DNA genomes express silencing suppressor proteins to guarantee their successful invasion (Ding and Voinnet 2007; Roth et al. 2004). It is believed that the mode of action differs between suppressors. For example, the P19 protein of Tomato bushy stunt virus (TBSV) binds the siRNA duplexes and prevents their entry into the RISC (Silhavy et al. 2002). The $2 \mathrm{~b}$ protein of Cucumber mosaic virus interacts with AGO1 and binds siRNA (Duan et al. 2012; González et al. 2010; Zhang et al. 2006) and may also interfere with the production of RDR1-dependent vsiRNAs (DiazPendon et al. 2007). The coat protein (CP) of Turnip crinkle virus could bind dsRNAs to prevent them from being processed by the Dicer-like RNase (Qu et al. 2003). P6 of Cauliflower mosaic virus (CaMV) interacts with the dsRNA-binding protein 4 (DRB4) and thereby decreases the activity of DCL4 (Haas et al. 2008). The P protein of Sonchus yellow net virus, the only suppressor protein identified in plant rhabdoviruses, was reported to suppress gene silencing via unknown mechanisms (Jackson et al. 2005).

Two major classes of endogenous small RNAs, miRNA and siRNA, have been extensively studied in plants. miRNAs are approximately 21 -nt noncoding RNAs produced by DCL-catalyzed excision from stem-loop precursors (Meyers et al. 2008), while siRNAs are processed from long dsRNAs produced by RDR. In addition to the differences in their biogenesis, these two classes of small RNAs also differ in their functions (Carthew and Sontheimer 2009). Interestingly, trans-acting siRNAs (ta-siRNAs), one class of endogenous siRNAs, are generated through the suppressor of gene silencing 3 (SGS3)/ RDR6/DCL4 pathway after miRNA-guided cleavage of the RNA transcribed from TAS genes (Peragine et al. 2004; Vaucheret 2005; Yoshikawa et al. 2005). Among them, TAS3 ta-siRNAs, which depend on the miR390-AGO7 complex and require two miR390 complementary sites for successful biogenesis, are conserved in plants, as indicated by bioinformatic analysis (Allen et al. 2005; Axtell et al. 2006; Montgomery et 
al. 2008). Ta-siRNAs function as negative regulators via interacting with the target transcripts and guiding their cleavage, mimicking the miRNA mechanism (Fahlgren et al. 2006; Vazquez et al. 2004).

Rice yellow stunt virus (RYSV) is a member of the Nucleorhabdovirus genus in the Rhabdoviridae family. It has a negative-sense, nonsegmented single-stranded RNA genome (Walker et al. 2000). The 12-kb genome contains a $5^{\prime}$ trailer, a $3^{\prime}$ leader, and seven open reading frames (ORF) ordered as $3^{\prime}$ le-N-P-3-M-G-6-L-5'-tr (Huang et al. 2003). The 3' proximal ORF-encoded $\mathrm{N}$ is a nucleocapsid protein (Fang et al. 1994) and $\mathrm{P}, \mathrm{M}, \mathrm{G}$, and $\mathrm{L}$ are the viral phosphoprotein (Zhu et al. 1997), matrix protein (Luo et al. 1998), glycoprotein (Luo and Fang 1998), and RNA-dependent RNA polymerase (RdRp) (Huang et al. 2003), respectively. ORF3 has been identified as encoding a movement protein (Huang et al. 2005). ORF6 is located between the $\mathrm{G}$ and $\mathrm{L}$ genes and encodes a 93-aa, acidic protein (designated P6) (Huang et al. 2003). Similar ORF have also been found in the equivalent locations in the genomes of Strawberry crinkle virus and Northern cereal mosaic virus (Jackson et al. 2005; Tanno et al. 2000). However, their encoded proteins share little sequence similarity with RYSV P6 (Huang et al. 2003). As a virion protein, P6 can be phosphorylated in vitro but its functions remain unclear (Huang et al. 2003).

Agrobacterium-mediated transient assay in Nicotiana benthamiana has been extensively exploited as an approach to investigate the mechanisms underlying the functions of viral suppressors of RNA silencing (VSR) (Qu et al. 2003). However, a similar transient expression system is not available for monocots like rice. Accordingly, the protoplast system has been developed as a transient assay to complement the existing approaches in such plants. Recent studies demonstrated that RNA silencing could be induced in protoplast systems by the delivery of silencing inducers, such as synthetic siRNAs, in vitro-transcribed dsRNAs, or plasmids encoding dsRNA (Chen et al. 2006; Qi et al. 2004; Vanitharani et al. 2003). Here, the rice protoplast system was employed to evaluate the RNAsilencing suppressor function of the RYSV P6 protein.

In this study, we showed that RYSV P6 enhanced the virulence of Potato virus $X$ (PVX) and inhibited systemic silencing induced by sense RNA or dsRNA in nonhost plants. Transiently expressing P6 in $N$. benthamiana leaves caused diminished accumulation of secondary siRNAs. In addition, we showed that P6 and RDR6 were colocalized in the nuclei and P6 can bind OsRDR6 and AtRDR6 in coimmunoprecipitation experiments. Furthermore, the transgenic rice plants expressing P6 became more sensitive to the infection of a tested virus, Rice stripe virus (RSV). Together, our results suggest that P6 is part of the RYSV's counter-defense system and interferes with RNA silencing by affecting the function of RDR6 during secondary siRNA synthesis.

\section{RESULTS}

\section{P6 enhanced virulence of PVX.}

To determine if RYSV P6 is related to the viral pathogenicity, we used a heterologous gene expression system based on an infectious PVX clone. $N$. benthamiana and N. tabacum SR1 plants were agroinfiltrated with plasmids expressing PVX, PVX-P6, or PVX-P $\Delta 6$, which contained a nontranslatable form of P6 mRNA due to a premature stop codon. Leaves of plants infiltrated with PVX or PVX-P $\Delta 6$ showed mild mosaic symptoms at 12 days postinfiltration (dpi), while those infiltrated with PVX-P6 showed more severe symptoms, including necrotic and chlorotic spots on leaves, leaf curling, and plant stunting (Fig. 1A to E; data in N. tabacum SR1 not shown).
These results showed that RYSV P6 could enhance pathogenicity when expressed from an engineered heterologous virus.

The accumulation of the PVX genomic and subgenomic RNAs (gRNAs and sgRNAs, respectively) in the plants infected with PVX, PVX-P6, or PVX-P $\Delta 6$ was checked. Total RNAs were extracted from systemic leaves of plants at $12 \mathrm{dpi}$. As shown in Figure 1F, the PVX gRNA mildly increased in the PVX-P6-infected $N$. benthamiana and $N$. tabacum SR1 plants. These results suggest that RYSV P6 acts as a pathogenicity determinant and this pathogenicity-enhancing activity is somewhat associated with viral RNA accumulation in the systemic leaves.

\section{P6 could not suppress local silencing in $N$. benthamiana.}

The ability of enhancing PVX virulence implied P6 might play a role in suppression of antiviral silencing pathway. In order to determine the activity of the P6 protein against local silencing, the agroinfiltration transient expression assay was used. An Agrobacterium strain harboring pBin61-P19 expressing TBSV silencing suppressor P19 was used as a positive control. When leaves of $N$. benthamiana line $16 \mathrm{c}$ plants were infiltrated with Agrobacterium strains harboring the plasmid pCAMBIA1302 that expresses the green flourescent protein (GFP), the infiltrated area appeared as a uniform red patch under UV light at 6 dpi, because the GFP gene was silenced locally (Fig. 2A). When the leaves of 16c were infiltrated with a mixture of Agrobacterium strains carrying GFP and P19, there was a marked increase in GFP fluorescence (Fig. 2A) and the high-level fluorescence persisted for at least 14 days. When 16c was infiltrated with Agrobacterium strains carrying GFP along with P6 or its mutant (pBA002-3HA-P6 or pBA002$3 \mathrm{HA}-\mathrm{P} \Delta 6$ ), there was no significant increase in the GFP fluorescence intensity in the infiltrated areas (Fig. 2A).

The results obtained from Northern blot analysis of the GFP mRNA were consistent with the observations of GFP fluorescence. There was a marked reduction in the accumulation of the GFP mRNA in leaves infiltrated with the Agrobacterium strain harboring GFP, and similar GFP mRNA reduction was observed in leaves infiltrated with GFP plus P6 or P $\Delta 6$. In contrast, there was increased accumulation of the GFP mRNA in leaves infiltrated with GFP plus P19 (Fig. 2B).

Abundant GFP-specific siRNAs of 21 to 24 nt were detected in leaves infiltrated with GFP alone, with GFP plus P6, or with GFP plus P $\Delta 6$, but not in those infiltrated with GFP plus P19 (Fig. 2B). To determine whether P6 was expressed in leaves infiltrated with GFP plus P6, total proteins were extracted and were analyzed by Western blot using monoclonal antibodies against hemagglutinin (HA) tag. The result showed that P6 was indeed present (Fig. 2C).

\section{P6 could prevent systemic silencing in $N$. benthamiana plants.}

After local silencing is initiated, the silencing signal can spread systemically throughout the plant (Dunoyer et al. 2010; Molnar et al. 2010). To investigate whether P6 affects this process, GFP fluorescence was monitored in upper leaves of $16 \mathrm{c}$ plants infiltrated with Agrobacterium strains carrying either GFP only (pCAMBIA1302) or GFP along with P6 or its mutant P $\Delta 6$ (pBA002-3HA-P6, pBA002-3HA-P $\Delta 6$, respectively). After $16 \mathrm{dpi}$, we observed red fluorescence in upper uninfiltrated leaves of GFP-infiltrated plants, an indication of systemic silencing. The red fluorescence was also visible in plants infiltrated with GFP plus P $\Delta 6$ (Fig. 2D). In contrast, upper leaves of plants infiltrated with GFP plus P6 or control TBSV suppressor P19 showed green fluorescence (Fig. 2D). As shown in Table 1, the efficiency of P6 to inhibit systemic silencing was $85.7 \%$ (18 of 21 plants showed inhibition of systemic silencing). $\mathrm{P} \Delta 6$ could not suppress systemic silencing, implying that 
the P6 protein but not its mRNA was responsible for the suppression function. Northern blot showed that new upper leaves of the 16c plants that emerged after infiltration with GFP plus P6 or P19 contained significant levels of GFP mRNA and undetectable GFP-specific siRNAs (Fig. 2E). Conversely, GFP siRNAs were detected and no GFP mRNA was found in the upper leaves when GFP alone or with $\mathrm{P} \Delta 6$ were used.

\section{P6 diminished accumulation of secondary siRNAs.}

The systemic spread of gene silencing mostly depends on the amplification of a silencing signal that likely contains siRNAs (Dunoyer et al. 2010; Molnar et al. 2010). The amplification process needs the RDR to duplicate the single-strand RNA templates to dsRNAs, which are subsequently processed into secondary siRNAs by DCL, a phenomenon known as transitivity (Moissiard et al. 2007). To study the underlying mechanism of inhibition of systemic silencing by P6, we explored its effect on transitivity, using the GFP gene as a test sample. An inverted-repeat construct corresponding to the $5^{\prime}$ part of the mgfp5 gene (covering 1 to $392 \mathrm{nt}$, named GF) was created. This construct, predicted to produce a dsRNA transcript composed of the sense strand GF and its complementary strand FG, was denoted as dsGF. Leaves of $N$. benthamiana were coagroinfiltrated with GFP, dsGF, and P6. Secondary siRNAs were visualized using probe $\mathrm{P}$, which recognizes the $3^{\prime}$ part of $m g f p 5$, the region outside of the GF. As expected, the patches infiltrated with GFP, dsGF, and P19 together displayed bright green fluorescence, while the patches infiltrated with GFP, dsGF, and P6 or P $\Delta 6$ displayed red fluorescence, which was consistent with the levels of GFP mRNA (Fig. 3A and B). dsGF-induced post-transcriptional gene silencing was verified by analyses of both GF primary and P secondary siRNAs at 3 and 6 dpi. The levels of primary siRNAs in P6-expressing patches were similar to those observed in mock and $\mathrm{P} \Delta 6$ expressing patches at $3 \mathrm{dpi}$ (Fig. 3B). At $6 \mathrm{dpi}$, the level of primary siRNA in P6 expression patches seemed lower than that in the mock and $\mathrm{P} \Delta 6$-expressing tissues. Interestingly, neither P19- nor P6-expressing tissues showed visible accumulation of secondary siRNA at 3 dpi (Fig. 3B). Taken together, these results suggest that RYSV P6 inhibited systemic silencing triggered by dsRNA through restricting the transitivity of the silencing signals.

\section{P6 interacted with RDR6 in vivo and they colocalized in the nuclei.}

The ability of P6 to inhibit the formation of secondary siRNAs suggested its interference with dsRNA processing, which involves the RDR6 activity. To test whether P6 interacts with RDR6, we infiltrated leaves of $N$. benthamiana with Agrobacterium strains expressing 3HA-P6 along with 6mycAtRDR6, 6myc-OsRDR6, or other control proteins. The results showed 3HA-P6 specifically coimmunoprecipitated with
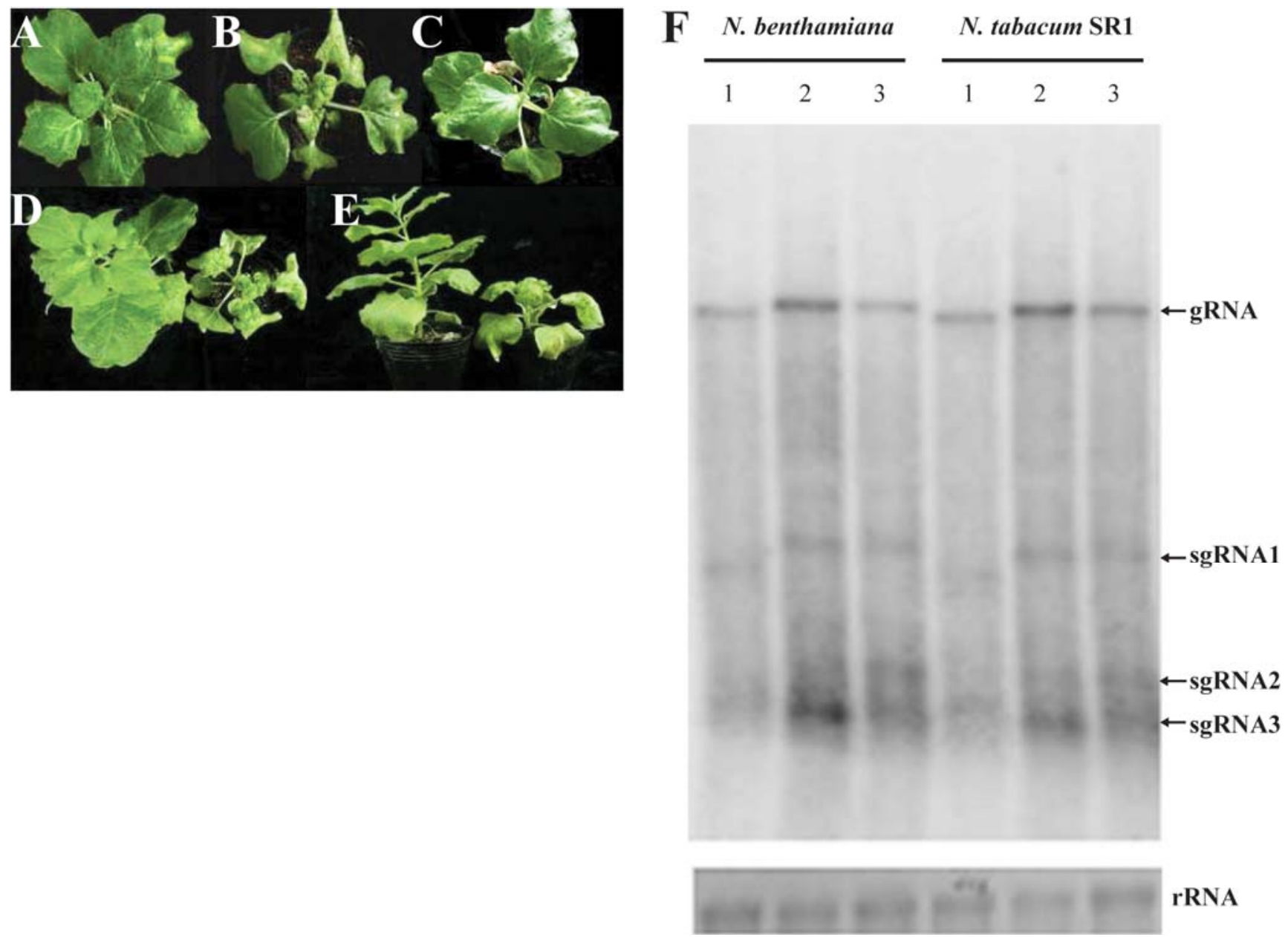

Fig. 1. Effect of Rice yellow stunt rhabdovirus P6 on virulence of Potato virus X (PVX) on Nicotiana benthamiana and N. tabacum SR1. A to E, N. benthamiana were agroinoculated with PVX (A, D left, and E left), PVX-P6 (B, D right, and E right), or PVX-P 66 (C). Photographs were taken at 12 days postinfiltration (dpi) (A to C) and 28 dpi (D and E). F, Northern blot analysis of accumulation of PVX genomic and subgenomic RNAs (gRNA and sgRNAs, respectively) in plants infected with PVX (lane 1), PVX-P6 (lane 2), or PVX-P $\Delta 6$ (lane 3 ) at 12 dpi, using a probe corresponding to the PVX coat protein gene. Methylene blue-stained rRNA served as a loading control. 
OsRDR6 and AtRDR6 but not with AtSGS3 or AtSDE3. All of these proteins were tagged with $6 \times \mathrm{myc}$ at their $\mathrm{N}$ termini (Fig. $4 \mathrm{~A})$.

The specific interaction between P6 and RDR6 was further confirmed by a subcellular colocalization experiment. Agrobacterium cells containing P6-enhanced cyan fluorescent protein (eCFP), and those containing enhanced yellow fluorescent protein (eYFP)-AtRDR6 were co-infiltrated into $N$. benthamiana leaves. The P6 protein exhibited localization in the nucleus and cell periphery, whereas eYFP-AtRDR6 was distributed throughout the nucleus and cytoplasm. Colocalization of P6eCFP and eYFP-AtRDR6 was found mainly in the nuclei but not at the cell periphery (Fig. 4B).

\section{P6 expression did not alter the expression level of ta-siRNAs in rice plants.}

To gain further insights into the mechanism of P6 function, we examined whether the presence of P6 affected the activity of RDR6 in rice, the natural host of RYSV. Previous reports showed that ta-siRNAs are generated through the SGS3/ RDR6/DCL4 pathway (Peragine et al. 2004; Yoshikawa et al. 2005). To quantify the expression of TAS3-related ta-siRNAs in transgenic rice plants expressing P6 (6myc-P6 and 3HA-P6), we conducted reverse transcription-polymerase chain reaction (RT-PCR) (data not shown), Western blot analyses, and Northern blot analyses. The results showed that P6 transgenic rice plants and controls had similar levels of Oryza sativa TAS3 5'D6(+) ta-siRNA (Supplementary Fig. S1). Collectively, our data suggest that transgenic rice plants expressing P6 do not influence the function of OsRDR6 in the biogenesis of ta-siRNAs.

Table 1. Suppression efficiency of systemic silencing in Nicotiana benthamiana line $16 \mathrm{c}^{\mathrm{a}}$

\begin{tabular}{lccc}
\hline Construct & $\begin{array}{c}\text { Infiltrated } \\
\text { plants }(\boldsymbol{n})\end{array}$ & $\begin{array}{c}\text { Systemic silencing } \\
\text { plants }(\boldsymbol{n})\end{array}$ & $\begin{array}{c}\text { Suppression } \\
\text { efficiency }(\boldsymbol{\%})\end{array}$ \\
\hline GFP & 16 & 15 & 6.25 \\
GFP+P $\Delta 6$ & 22 & 18 & 18.1 \\
GFP+P6 & 21 & 3 & 85.7 \\
GFP+P19 & 15 & 1 & 93.3 \\
\hline
\end{tabular}

${ }^{a}$ Agrobacterium strains carrying indicated constructs were agroinfiltrated to $N$. benthamiana line $16 \mathrm{c}$ and the green fluorescence was monitored under a long-wave UV lamp to detect the suppression efficiency of systemic silencing at 16 days postinfiltration (dpi). $n=$ number of plants.
A

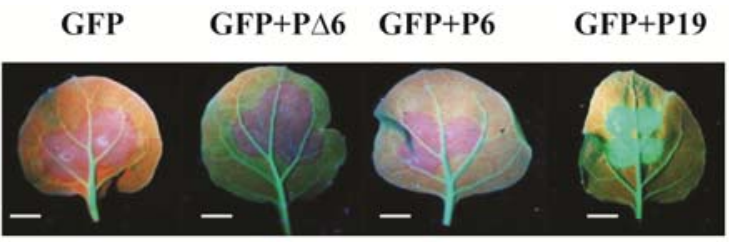

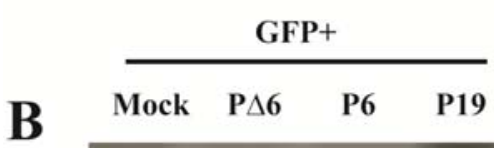

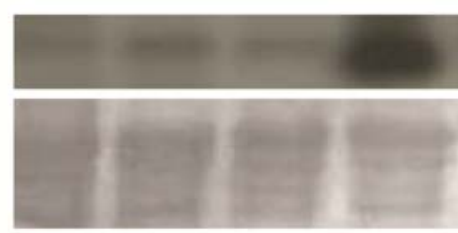

GFP mRNA

Methylene blue staining

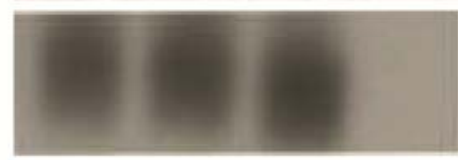

GFP siRNAs

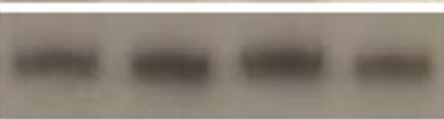

C

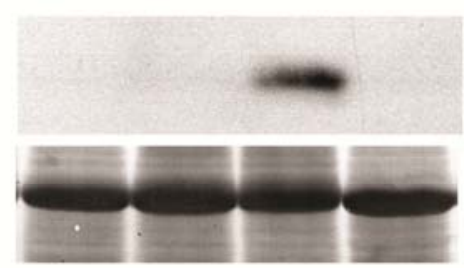

D

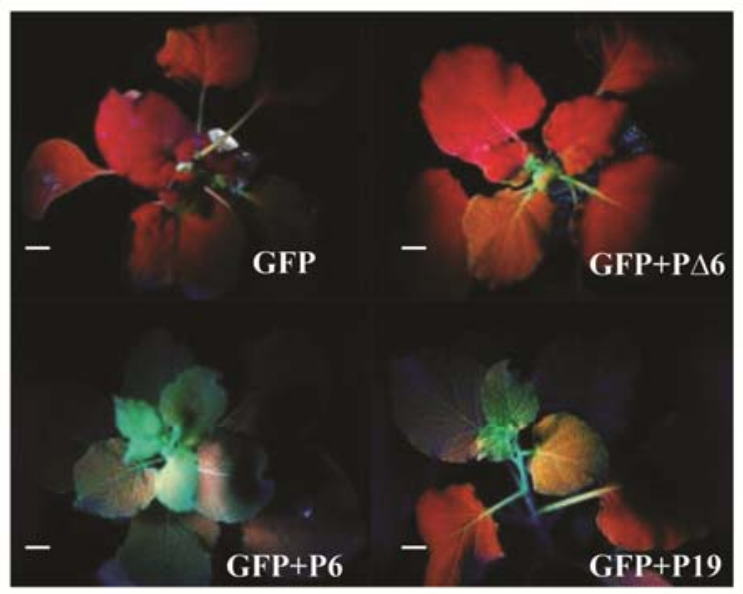

$\mathbf{E}$

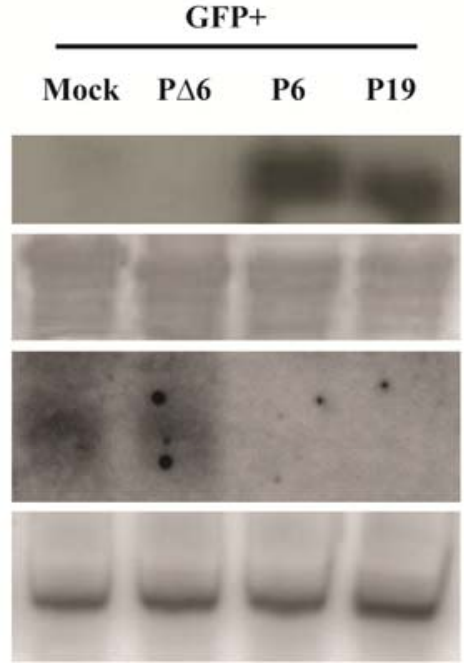

U6 SnRNA

GFP mRNA

Methylene blue staining

Anti-HA

RUBISCO
GFP siRNAs

U6 SnRNA

Fig. 2. Transient expression assay in leaves of Nicotiana benthamiana line 16c and suppression effect of Rice yellow stunt rhabdovirus P6 on systemic silencing caused by sense GFP (plasmid pCAMBIA1302, which expresses the green flourescent protein) RNA. A, Leaves were infiltrated with suspensions of Agrobacterium tumefaciens carrying different constructs as indicated above the figure. Leaves were photographed at 6 days postinfiltration (dpi). B, Northern blot analysis of accumulation of GFP mRNA and GFP siRNAs in leaves infiltrated with agrobacteria harboring indicated constructs. C, Western blot analysis of 3HA-P6 protein expressed in N. benthamiana line 16c leaves infiltrated with Agrobacterium strains carrying GFP and 3HA-P6 using specific monoclonal antibodies against the hemagglutinin (HA) tag. Coomassie Brilliant Blue staining of the large subunit of RUBISCO served as a loading control. D, Plants of N. benthamiana line 16c agroinfiltrated with Agrobacterium strains carrying indicated constructs were photographed with a yellow filter under a long-wave UV lamp at 16 dpi. E, Northern blotting of GFP mRNA and GFP siRNAs extracted from newly emerged leaves of infiltrated plant at 16 dpi. Methylene blue staining and U6 hybridization served as loading controls for mRNA and siRNA, respectively. Scale bar $=1 \mathrm{~cm}$. 
P6 did not suppress dsRNA-induced silencing in rice protoplasts.

The rice protoplast system was used to study the suppression activity of P6 in rice cells. An inverted-repeat construct,
dseGF, similar to dsGF but corresponding to the $5^{\prime}$ part of the eGFP gene (eGF) was created. We cotransformed plasmids of eGFP, dseGF with P6, P $\Delta 6$, or P19 (pX-DR-3HA-P6, $\mathrm{pX}-\mathrm{DR}-3 \mathrm{HA}-\mathrm{P} \Delta 6$, and $\mathrm{pX}-\mathrm{DR}-3 \mathrm{HA}-\mathrm{P} 19$, respectively) into

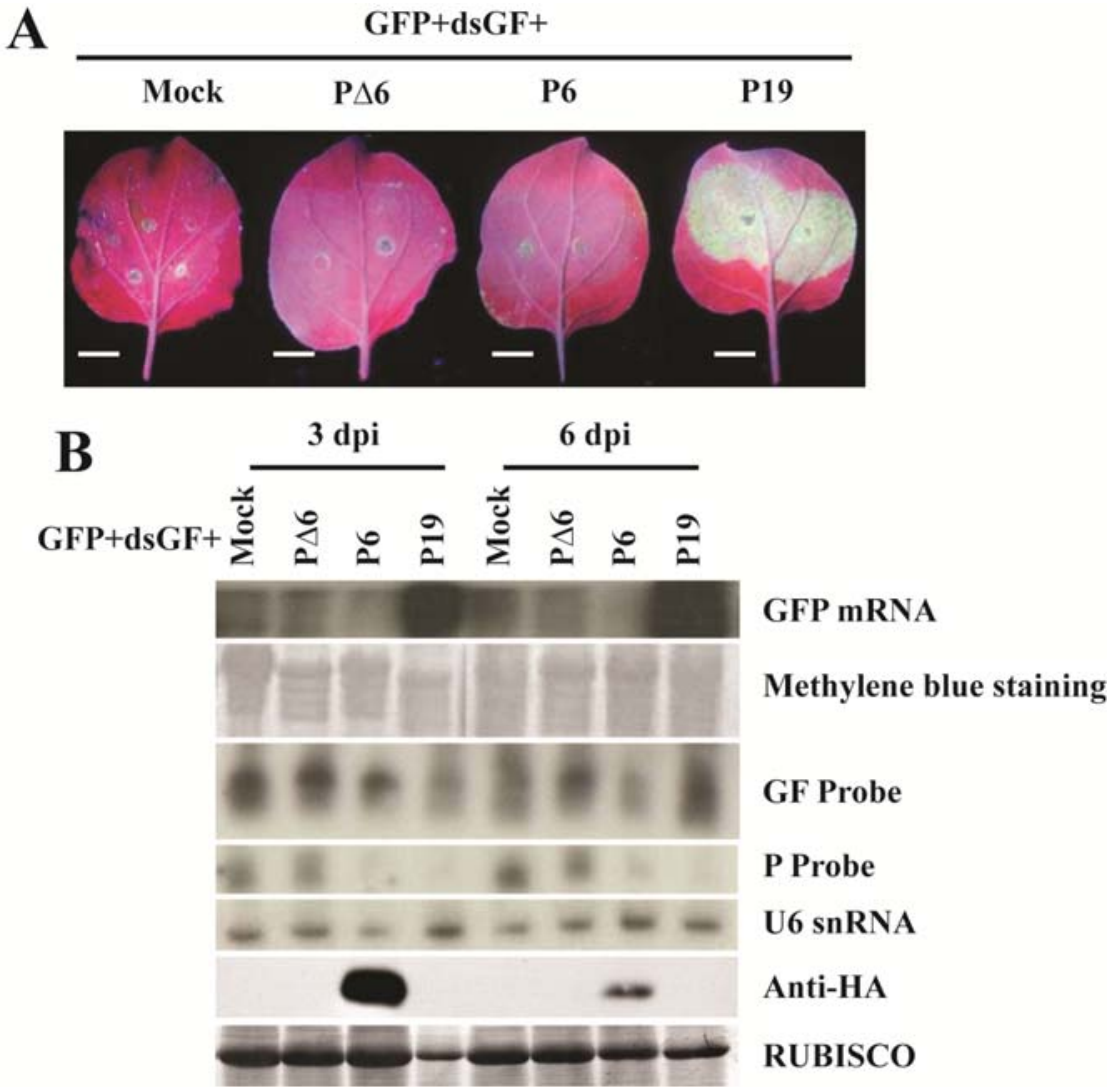

Fig. 3. Effect of P6 protein on primary and secondary siRNA accumulation. A, Nicotiana benthamiana plants were agroinfiltrated with agrobacteria containing GFP construct (plasmid pCAMBIA1302 which expresses the green flourescent protein), dsGF, and buffer (mock), P $\Delta 6$, P6, or P19. Photographs were taken at 6 days postinfiltration (dpi). Scale bar $=1 \mathrm{~cm}$. B, RNAs were extracted at 3 and $6 \mathrm{dpi}$, respectively, and were analyzed for the presence of GFP mRNA and siRNA. Small RNAs were hybridized with specific probes for the GF or P parts of GFP. Methylene blue staining and U6 hybridization served as loading controls for mRNA and siRNA, respectively. Expression of P6 was confirmed by Western blotting, using monoclonal hemagglutinin (HA) antibodies. Coomassie Brilliant Blue staining of the large subunit of RUBISCO served as a protein loading control.
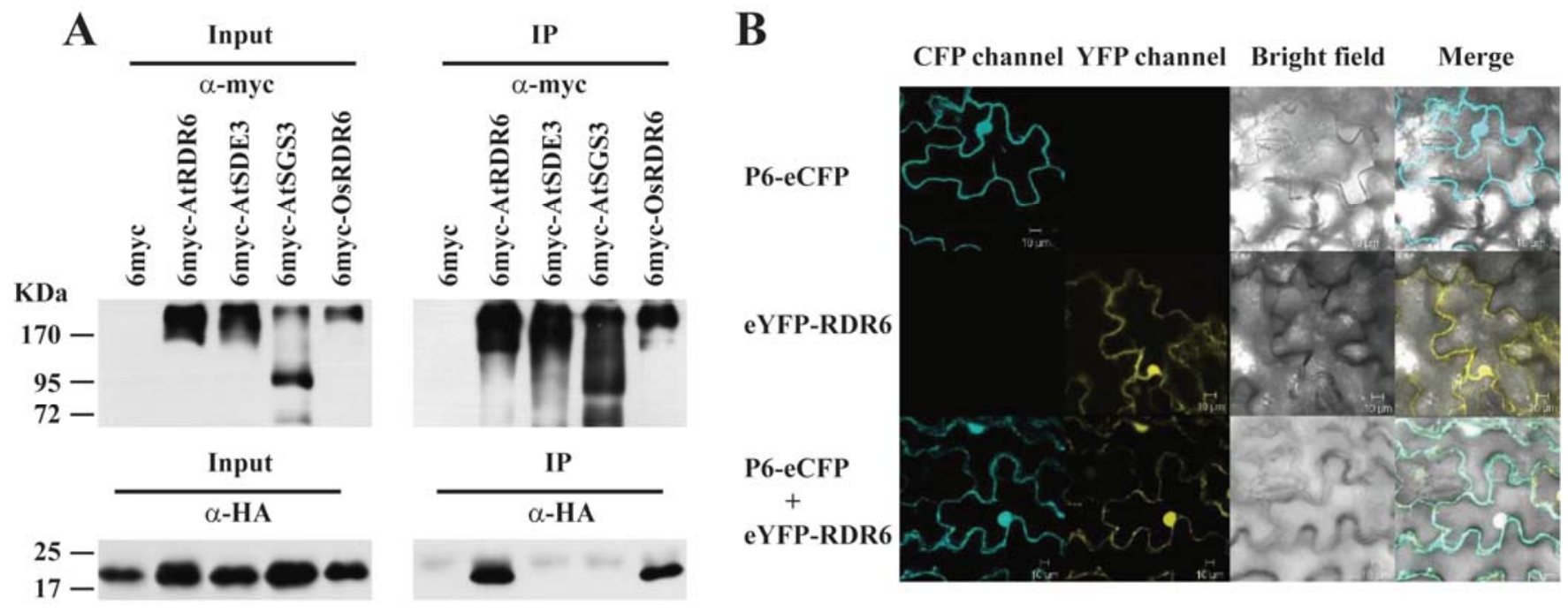

Fig. 4. Interaction between P6 and RDR6 in vivo and intracellular localization of P6-eCFP and eYFP-AtRDR6. A, 3HA-P6 was coexpressed with 6mycAtRDR6, 6myc-AtSDE3, 6myc-AtSGS3, or 6myc-OsRDR6 in Nicotiana benthamiana. Total soluble proteins were extracted (Input) and immunoprecipitated (IP) with anti-c-myc M2 affinity gel. Western blot was carried out using monoclonal myc or hemagglutinin (HA) antibodies to detect myc-tagged proteins (top panels) or coimmunoprecipitated HA-tagged P6 protein (bottom panels), respectively. B, Agrobacterium cells were co-infiltrated into leaves of $N$. benthamiana. Co-localization of P6-eCFP and eYFP-AtRDR6 was observed mainly in the nucleus. Infiltration with P6-eCFP or eYFP-AtRDR6 was used as controls. All images were taken at the same magnification. Scale bar $=10 \mu \mathrm{m}$. 
the protoplasts at a weight ratio of 1:4:4. By $10 \mathrm{~h}$ post-transformation, the RNAs were isolated and were analyzed by RNA gel blotting.

As shown in Figure 5A, codelivery of eGFP and silencing inducer dseGF caused a drastic reduction in eGFP mRNA. This silencing effect was prevented in the presence of P19 but not in the presence of $\mathrm{P} 6$ or $\mathrm{P} \Delta 6$. These results in rice protoplasts were in accordance with the results we obtained in $N$. benthamiana leaves (Fig. 3B). Five independent experiments produced essentially the same results.

The expression level of eGF primary siRNAs and eP secondary siRNAs were also analyzed, using RNA gel blots. The results showed that the presence of P6 could slightly decrease the eGF primary siRNA expression but $\mathrm{P} \Delta 6$ or P19 had no effects. As shown in the middle panel of Figure 5B, the expression of eP secondary siRNAs was undetectable. The expression of suppressors fused with DsRed and tagged with HA was confirmed by Western blot (Fig. 5C).

\section{Transgenic rice plants expressing P6 showed} enhanced sensitivity to RSV.

The above data suggested that P6 is a part of the counterRNA silencing system in RYSV. By inference, the P6 trans-

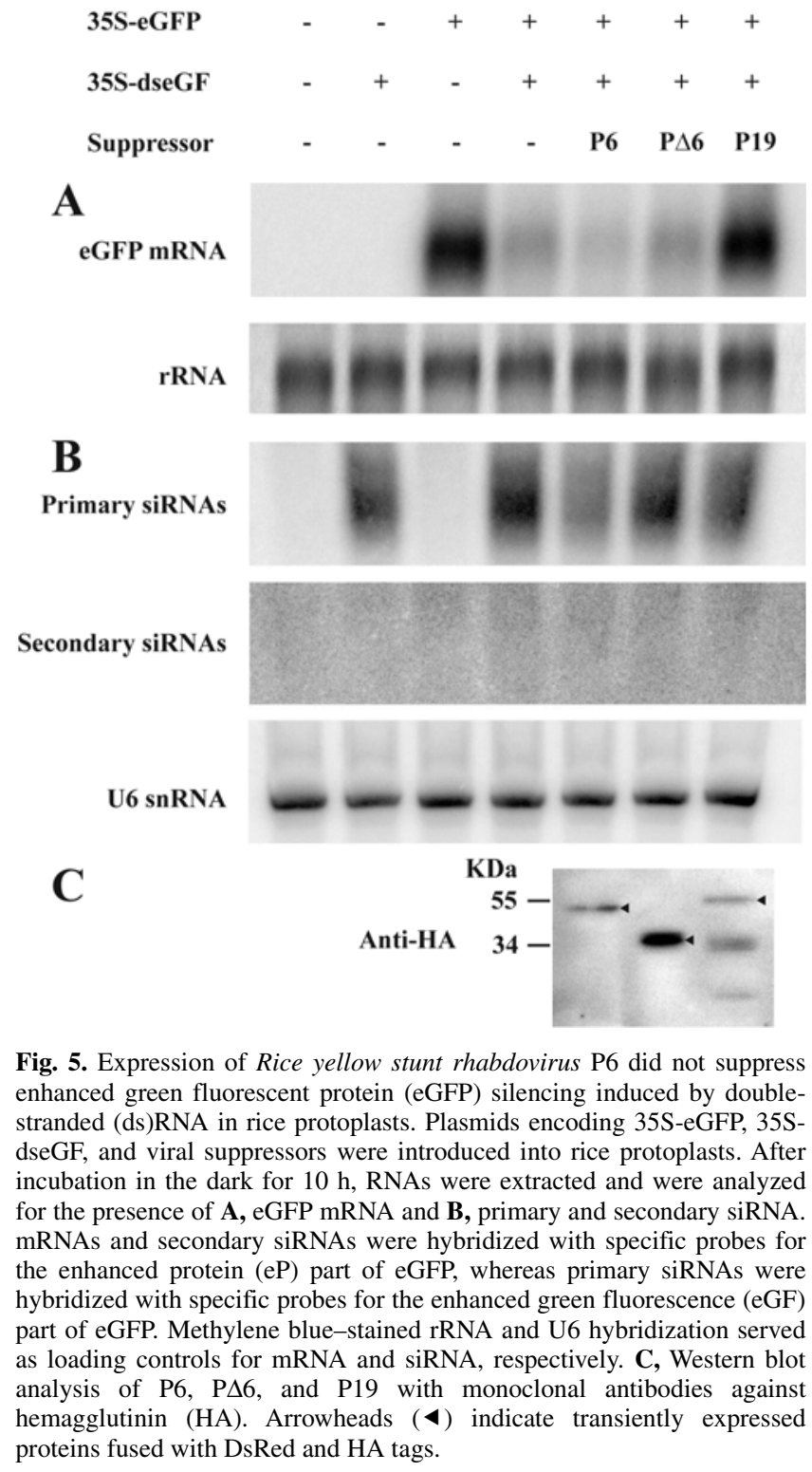

genic plants may be more sensitive to virus infection than untransformed plants. Six independent P6 transgenic rice lines and untransformed wild-type rice plants were challenged with $\mathrm{RSV}$, and the infected plants were harvested at 3 and 9 days postinoculation (six plants of each transgenic line and control plants). Total RNAs of inoculated plants (mixture of six plants) were isolated and levels of NSvc3 RNA (encoding the RSV $\mathrm{CP}$ protein) were quantified by quantitative RT-PCR. The results showed that there were larger quantities of the RSV RNA in most transgenic lines compared with the control plants (Fig. 6). These results suggest that the presence of the RYSV P6 protein facilitates the viral RNA accumulation via its RNA silencing suppressor activity.

\section{DISCUSSION}

RNA silencing is a defense strategy evolved by plants and other eukaryotic organisms against invading microbes such as viruses. As a counterdefense, viruses have evolved silencing suppressors that target multiple steps of the RNA silencing pathway of their hosts (Burgyán and Havelda 2011; Wu et al. 2010). Many VSR have been identified from RNA and DNA viruses with diverse functions (Bisaro 2006; Qu and Morris 2005).

P6 is a structural protein of RYSV with unknown functions. Transgenic rice plants expressing P6 did not show any significant change in morphology and were more susceptible to virus infection than untransformed plants. Expression of RYSV P6 by PVX enhances the virulence of the heterologous virus PVX in $N$. benthamiana, $N$. tabacum SR1, and $N$. glutinosa (data not shown). Symptoms in the leaves of the above plants infiltrated with PVX-P6, e.g., chlorotic spots, stunting, and leaf yellowing, were also observed in RYSV-infected rice (Hibino 1996). Interestingly, this phenotype resembles the symptoms of PVX infection in RDR6-knockdown plants (Schwach et al. 2005). Taken together, our data imply that RYSV P6 possesses VSR functions in vivo. Specifically, our data suggest that RYSV P6 interferes with the function of the host plant RDR6 protein.

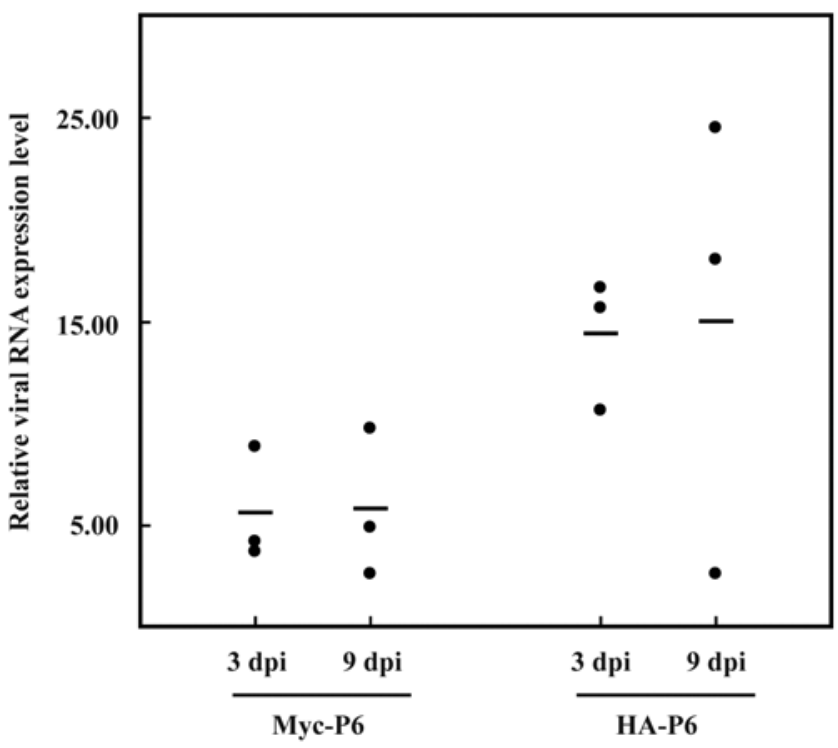

Fig. 6. Rice stripe virus (RSV) RNA expression level in the P6 transgenic rice lines (Myc-P6 and HA-P6) after RSV infection. Levels of the RSV NSvc3 transcripts were analyzed by quantitative reverse transcriptionpolymerase chain reaction at 3 and 9 days postinoculation. The NSvc3 expression levels were normalized using the signal from the rice actin gene. The accumulation level of RSV NSvc3 in the wild-type rice plants was set to 1.0. Three biological repeats are shown (solid circles). Horizontal bars represent the average values. 
The RNA silencing signals are amplified with the help of host proteins such as RDR6, SGS3, SDE3, and others in a process known as transitivity (Himber et al. 2003). The results from this study showed that the P6 protein could inhibit systemic RNA silencing by restricting the transitivity of the silencing signals triggered by dsRNA but had no effect on local RNA silencing. Coimmunoprecipitation experiments showed specific interaction of P6 with RDR6 but not with SGS3 or SDE3. However, no evidence for a direct or indirect interaction between P6 and RDR6 within the immunoprecipitated complex is known. P6 was colocalized with RDR6 in the nuclei. This suggests that P6 might inhibit amplification of the silencing signals by interfering with the activity of RDR6. Since RDR6 is indispensable for RNA silencing signal movement, we propose that P6-RDR6 interaction may limit the accumulation of secondary siRNAs, thereby inhibiting non-cell autonomous silencing. The levels of TAS3 ta-siRNAs in P6 transgenic rice plants were similar to those in control rice plants, probably because the expression level of P6 in transgenic plants was too low to affect the function of RDR6 in producing ta-siRNAs. The possibility that other RYSV proteins function with P6 to regulate the biogenesis of secondary siRNAs during viral infection cannot be ruled out. It was reported that RDR6 colocalized with SGS3 in cytoplasmic granules (Kumakura et al. 2009). It may also be interesting to investigate the role of SGS3 in the P6RDR6 partnership in future studies.

Unlike the TBSV silencing suppressor P19 that functions by binding 21- to 25-nt siRNAs (Silhavy et al. 2002) and the polerovirus protein $\mathrm{P} 0$, which inhibits the formation of secondary siRNAs and the local silencing by degrading the AGO1 protein (Baumberger et al. 2007; Bortolamiol et al. 2007), P6 neither interferes with local silencing nor binds 21-nt siRNA (Supplementary Fig. S2). PVX-P6 infected plants showed more severe symptoms and increased PVX genomic RNA levels compared with the control plants. Based on our study, we propose that P6 acts as a pathogenicity determinant, at least partially as a result of its counter-RNA silencing effects.

In the rice protoplast-based transient RNA silencing system, P6 could not interfere with RNA silencing triggered by dsRNA. Since this transient assay is conducted in single cells, it is not a good choice to study systemic silencing (Qi et al. 2004). We also did not detect secondary siRNAs in this system, probably because the end point analysis was performed $10 \mathrm{~h}$ post-transformation. Transgenic rice plants expressing P6 were more susceptible to RSV infection, resulting in higher levels of viral RNA accumulation than in infected control plants. We observed at least twofold higher levels of RSV RNA accumulated in HA-P6 transgenic rice lines than in Myc-P6 lines. Whether different fusion tags affect the partner protein differentially in its solubility or stability remains to be studied.

The role of RYSV P6 in the virus-insect vector interaction is still unknown. The P6 protein can be detected in viruliferous vector leafhoppers (Huang et al. 2003). Even though RNA interference directs innate immunity against pathogens in insect organisms (Wang et al. 2006), there is no RdRP homolog identified in any insect genomes until now (Gordon and Waterhouse 2007; Zong et al. 2009). It will be interesting to investigate the roles of RYSV P6 in the insect vector cells.

\section{MATERIALS AND METHODS}

\section{Plasmid construction.}

The plasmid pBin61-P19 was provided by D. C. Baulcombe (Department of Plant Sciences, University of Cambridge, Cambridge, U.K.). For construction of dsGF, a GF fragment (corresponding to the $5^{\prime} 1$ to 392 nt sequence of mgfp5) was amplified from pCAMBIA1302 using two pairs of primers:
GF-F1 5'-AAAACTCGAGCCCGGGAGAAGAACTTTTCAC TG-3'; GF-R1 5'-AAAAAAGCTTCCTTAAGCTCGATCCTG3'; GF-F2 5'-AAAAACTAGTGGAGAAGAACTTTTCACTG3'; GF-R2 5'-AAAAGAATTCCCCTTAAGCTCGATCCTG-3'. Restriction sites (underlined) were added to these primers as follows: XhoI and HindIII sites with the first primer pair, SpeI and EcoRI sites with the second primer pair. The PCR-generated fragments, XhoI-GF-HindIII and EcoRI-FG-SpeI encoding sense and antisense mgfp5 $5^{\prime}$ proximal RNAs, respectively, were inserted into the plasmid pSK-intron (Guo et al. 2003) at the $5^{\prime}$ and $3^{\prime}$ arms of the intron between appropriate restriction sites to generate pSK-dsGF. After digestion with SmaI and SacI, the fragment containing the sense GF, intron, and antisense FG sequence was purified and was ligated to pBI121 (Jefferson 1987; purchased from Clontech, Palo Alto, CA, U.S.A.) digested with the same enzymes. The resulting plasmid was denoted pBI-dsGF.

Similarly, dseGF, which produces a dsRNA consisting of the strand eGF (corresponding to nt 34 to 373 of the eGFP $5^{\prime}$ terminal sequence) and its complementary strand eFG, was constructed by amplifying an eGF fragment (corresponding to $\mathrm{nt}$ 34 to 373 of the eGFP $5^{\prime}$ terminal sequence) from pBI221eGFP, using two pairs of primers: eGF-F1 5'-AAAACTC GAGCCCGGGGTGGTGCCCATCCTGGTCGA-3'; eGF-R1 5'-AAAAAAGCTTCGATGCGGTTCACCAGGGTGT-3'; eGF-F2 5'-AAAA A-3'; eGF-R2 5'-AAAAGAATTCCGATGCGGTTCACCAG GGTGT-3'. The PCR-generated fragments, XhoI-eGF-HindIII and EcoRI-eFG-SpeI were inserted into the plasmid pSKintron to generate pSK-dseGF. After digestion with SmaI and SacI, the fragment containing the sense eGF, intron and antisense eFG DNA sequences was purified and ligated to pBI221 (Jefferson 1987; purchased from Clontech) to obtain pBI-dseGF.

The binary vector pBA002, consisting of the CaMV 35S promoter, the nopaline synthase terminator, and a $6 \times$ myc tag or a $3 \times$ HA tag attached, was used for Agrobacterium infiltration experiments (Zhang et al. 2005). The ORF6 encoding the P6 protein was amplified by PCR, using the following two primers: P6-F1 5'-AAAACCCGGGATGTCCAGCCAACAAG AAAC-3' (SmaI site underlined) and P6-R1 5'-AAAAGAGCT CTTAATCTGGCCAGCCGTTGCA-3' (SacI site underlined). A nontranslatable mutant DNA fragment of P6, which had a single nucleotide substitution ( $\mathrm{G}$ to $\mathrm{T})$ that converted the sixth codon ( $\underline{\mathrm{G} A A})$ of ORF6 to a stop codon (TAA), was amplified by PCR using two primers: P $\triangle 6$-F 5'-AAAACCCGGGATGT CCAGCCAACAATAAAC-3' (SmaI site underlined) and P6$\mathrm{R} 1$ as stated above. The purified PCR products were double digested with SmaI and SacI and were inserted into pBA0026 myc or pBA002-3HA to generate pBA002-6myc-P6 or pBA002-3HA-P6, pBA002-6myc-P $\Delta 6$ or pBA002-3HA-P $\Delta 6$. Then the 3HA-P6, 3HA-P 66 fragments were amplified from pBA002-3HA-P6 and pBA002-3HA-P $\Delta 6$, with the primers as follows: t-3HA-F 5'-tATGTATCCTTATGATGTTCCAGA-3', P6-R2 5'-TTAATCTGGCCAGCCGTTGCA-3'. After purification, the DNA fragments were ligated to the vector $\mathrm{pX}-\mathrm{DR}$ (Chen et al. 2009), digested with XcmI enzyme, to obtain pXDR-3HA-P6, pX-DR-3HA-P $\Delta 6$. pX-DR-3HA-P19 was constructed using a similar method.

The RDR6, SGS3, and SDE3 genes of Arabidopsis were amplified from RT products of mRNA extracted from Arabidopsis thaliana (Col-0) plant leaves using the following primers: AtRDR6-F 5'-AAAACCCGGGTTATGGGGTCA GAGGGAAAT-3', AtRDR6-R 5'-AAAATTAATTAATTAGA GACGCTGAGCAAG-3', AtSGS3-F 5'-AAAACCCGGGTTA TGAGTTCTAGGGCTGGT-3', AtSGS3-R 5'-AAAAGAGCT CTTATCAATCATCTTCATTGTGAAG-3'; AtSDE3-F 5'- AA AA 
5'-AAAATTAATTAATTACTTCCACCCATCAGACCAC TC-3'. SmaI sites (underlined) were added to the forward primers, and PacI or $S a c \mathrm{I}$ sites (underlined) were added to the reverse primers. The PCR products of AtRDR6, AtSGS3, and AtSDE3 were double digested with SmaI and PacI or SacI and were ligated to pBA002-6myc previously restricted with the same enzymes, to produce pBA002-6myc-AtRDR6, pBA0026myc-AtSGS3, and pBA002-6myc-AtSDE3, respectively. OsRDR6, also known as rice SHOOTLESS2 (SHL2) (Nagasaki et al. 2007), was amplified from cDNA of Oryza sativa seedlings with the primers OsRDR6-F 5'-AAAATTAATTAACA TGCGATCGCCGCGCGGCGGGGCGG-3' (PacI site underlined) and OsRDR6-R 5'-AAAAGAGCTCTCATATCCTCTC GGAGATGTATGCTGCAAG-3' (SacI site underlined). The PCR product was double digested with PacI and SacI and ligated to pBA002-6myc previously restricted with the same enzymes to obtain pBA002-6myc-OsRDR6.

To prepare a CaMV $35 \mathrm{~S}$ promoter-driven construct expressing P6-eCFP fusion protein, the P6 gene was amplified with primers P6-F3 5'-AAAAGGATCCGCATGTCCAGCCAACA AG-3' and P6-R3 5'-AAAACCATGGTATCTGGCCAGCCGT TGCA-3'. A BamHI site was introduced into the forward primer and an NcoI site into the reverse primer (underlined). The purified PCR product was digested with BamHI and NcoI and was ligated to pCAMBIA1300-eCFP previously restricted with the same enzymes, to obtain pCAMBIA1300-P6-eCFP. The eYFP gene was amplified with primer eYFP-F 5'-AAAA TCTAGATGGTGAGCAAGGGCGAG-3' and eYFP-R 5'-AA AACCCGGGGCTTGTACAGCTCGTCCATGC-3'. An XbaI site was introduced into the forward primer and a SmaI site was introduced into the reverse primer (underlined). The purified PCR product was digested with $X b a \mathrm{I}$ and $S m a \mathrm{I}$ and was ligated to pBA002-6myc-AtRDR6 previously restricted with the same enzymes, to obtain pBA002-eYFP-AtRDR6.

The full-length cDNA clone of PVX, pP2C2S, was provided by D. C. Baulcombe. The full-length cDNA of PVX was introduced into pBI121 vector in two steps. First, the $5^{\prime}$ end (nt 1 to 550) of the PVX genome was amplified by PCR, using a forward primer corresponding to the $5^{\prime}$ end of the PVX genome (5'-ggactagtGAAAACTAAACCATACAC-3') incorporating a SpeI site (underlined, additional nucleotides in lowercase) and a reverse primer (5'-TCGGATCCAAGAAGTGCAG-3'), corresponding to nucleotides from positions 550 to $533 \mathrm{nt}$ of the PVX genome and containing a BamHI site (underlined). The resulting PCR product was double digested with SpeI and $B a m \mathrm{HI}$ and was inserted between the $\mathrm{Xba \textrm {I }}$ and BamHI sites of pBI121 to produce the plasmid pPVX550. Then, the pP2C2S was double digested with BamHI and SacI, and the remaining part of the PVX genome was inserted into the BamHI and SacI sites of pPVX550 to yield pBI121-PVX. ORF6 and the nontranslatable mutant (discussed above) were obtained by PCR amplification, using pSK-P6 as template. An EcoRV and a SalI site were introduced in the forward and the reverse primers, respectively. The PCR products were then digested with EcoRV and SalI and were ligated into pP2C2S between the EcoRV and SalI sites. The resulting plasmids were double digested with $B a m \mathrm{HI}$ and $S a c \mathrm{I}$ and were ligated into the BamHI and SacI sites of pPVX550, to yield pBI121-PVX-P6 and pBI121-PVX-P $\Delta 6$.

The binary vector pCAMBIA1300-221, a derivative of pCAMBIA1300, was used for rice transformation. After double digestion with HindIII and SacI, the fragment of pBA002-6myc-P6 or pBA002-3HA-P6 containing the CaMV $35 \mathrm{~S}$ promoter and 6myc-P6 or 3HA-P6 was ligated with pCAMBIA1300-221 digested with the same enzymes to yield pCAMBIA1300-6myc-P6 or pCAMBIA1300-3HA-P6, respectively.
Plant materials, agroinfiltration, GFP imaging, and rice transformation.

$N$. benthamiana, $N$. tabacum SR1, GFP transgenic $N$. benthamiana (line 16c), and Oryza sativa spp. japonica cv. Nipponbare plants were kept under incubator conditions with $25^{\circ} \mathrm{C} 16 \mathrm{~h}$ of light and $8 \mathrm{~h}$ of dark. The Agrobacterium infiltration method has been described previously (Brigneti et al. 1998). GFP fluorescence was observed using a long-wave UV lamp (Black Ray model B 100AP; UV products, Upland, CA, U.S.A.) and was photographed with a Nikon 9500 digital camera equipped with a Kenko yellow lens (Tokyo).

Agrobacterium-mediated transformation of rice was performed as described previously with some modifications (Hiei et al. 1994). Briefly, we used actively growing calli induced from the scutella of mature seeds and cocultivated for $20 \mathrm{~min}$ with Agrobacterium tumefaciens EHA105 harboring the gene of interest in cell suspension containing $100 \mathrm{mM}$ acetosyringone. After incubation at $28^{\circ} \mathrm{C}$ in the dark for $48 \mathrm{~h}$ on solid cocultivation medium, the calli were transferred twice to the selection medium containing $250 \mathrm{mg}$ of carbenicillin per liter, each, for 2 weeks. Then the calli were plated on the regeneration medium to obtain transgenic plants.

\section{Rice protoplast preparation and transformation.}

Young rice seedlings 10 - to 14-days postgermination were harvested; the leaf and stem tissues were cut into approximately $0.5-\mathrm{mm}$ strips, using a sharp razor, and were soaked in $0.6 \mathrm{M}$ mannitol. The soaked diced tissues were collected, transferred to the enzyme solution $(0.6 \mathrm{M}$ mannitol, $10 \mathrm{mM}$ MES at $\mathrm{pH} 5.7,1.5 \%$ cellulase $\mathrm{RS}, 0.75 \%$ macerozyme $\mathrm{R}-10$, $1 \mathrm{mM} \mathrm{CaCl} 2,0.1 \%$ bovine serum albumin, $5 \mathrm{mM} \beta$-mercaptoethanol, and $50 \mu \mathrm{g}$ of carbenicillin per milliliter), digested at $28^{\circ} \mathrm{C}$ for $4 \mathrm{~h}$ in the dark under gentle shaking $(50 \mathrm{rpm})$, and filtered through $35-\mu \mathrm{m}$ nylon mesh. The protoplasts were collected by centrifuging at $150 \times g$ for 5 min from the filtrate. After washing twice with W5 solution $(154 \mathrm{mM} \mathrm{NaCl}, 125$ $\mathrm{mM} \mathrm{CaCl}_{2}, 5 \mathrm{mM} \mathrm{KCl}, 2 \mathrm{mM} \mathrm{MES}$ at $\left.\mathrm{pH} 5.7\right)$, the protoplasts were resuspended in MMG solution $(0.6 \mathrm{M}$ mannitol, $15 \mathrm{mM}$ $\mathrm{MgCl}_{2}, 4 \mathrm{mM} \mathrm{MES}$ at $\left.\mathrm{pH} 5.7\right)$ at a concentration of $1 \times 10^{6}$ cells/ml for polyethylene glycol (PEG)-mediated transformation.

Plasmid DNAs were mixed with $300 \mu \mathrm{l}$ of resuspended protoplasts $\left(3 \times 10^{5}\right.$ cells $), 330 \mu \mathrm{l}$ PEG solution (0.6 M mannitol, $100 \mathrm{mM} \mathrm{CaCl} 2,40 \%$ (wt/vol) PEG 3350). For cotransfection, $2 \mu \mathrm{g}$ of pBI221-eGFP, $8 \mu \mathrm{g}$ of pBI-dseGF, and $8 \mu \mathrm{g}$ of suppressor expression plasmids were used. The mixture was gently shaken and incubated at room temperature for $15 \mathrm{~min}$. Following the incubation, $1.0 \mathrm{ml}$ of $\mathrm{W} 5$ solution was added and mixed gently by inverting the tube, and the protoplasts were pelleted by centrifuging at $150 \times g$ for $3 \mathrm{~min}$. After being washed once more with W5 solution, the protoplasts were resuspended in $1.5 \mathrm{ml}$ of W5 solution and were cultured in the dark at $28^{\circ} \mathrm{C}$ for $10 \mathrm{~h}$.

\section{Northern blot analysis.}

Total RNAs were extracted from plant tissues using TRIzol (Invitrogen, Carlsbad, CA, U.S.A.) according to the manufacturer's instructions. To detect PVX gRNA and GFP mRNA, 1 to $5 \mu \mathrm{g}$ of RNA samples were separated on $1.2 \%$ agarose gels containing $1.0 \%$ formaldehyde and were transferred to Amersham Hybond $\mathrm{N}+$ membranes (GE Healthcare, Buckinghamshire, U.K.). To detect siRNAs, 10 to $50 \mu \mathrm{g}$ of total RNA samples were separated on $7 \mathrm{M}$ urea and $15 \%$ polyacrylamide gels and were transferred to Amersham Hybond $\mathrm{N}+$ membranes. For ta-siRNA hybridization, $80 \mu \mathrm{g}$ of total RNA was separated and transferred in the same way as for siRNA detection. The probes for PVX gRNA, GFP mRNA, and siRNAs were ${ }^{32} \mathrm{P}-\mathrm{la}-$ 
beled using the Amersham Rediprime II DNA labeling system (GE Healthcare). Specifically, the probe to detect PVX gRNA corresponded to the PVX coat protein gene. Locked nucleic acid (LNA)-modified oligonucleotide complementary to Oryza sativa TAS3 ta-siRNA (5'-gtgggtcttacaAgGtCaAgaa-3', LNA nucleotides are shown in uppercase) was purchased from Exiqon A/S (Skelstedet 16, Vedbaek, Denmark) and labeled with ${ }^{32} \mathrm{P}$ on the $5^{\prime}$-end (Liu et al. 2007).

\section{Coimmunoprecipitation and Western blot experiments.}

Four-week-old $N$. benthamiana plants were infiltrated with Agrobacterium tumefaciens carrying pBA002-3HA-P6 together with Agrobacterium tumefaciens carrying pBA002-6mycAtRDR6, pBA002-6myc-AtSDE3, pBA002-6myc-AtSGS3, pBA002-6myc-OsRDR6, or pBA002-6myc as a negative control. After 2 days, total proteins were extracted from $2 \mathrm{~g}$ of leaf tissue with $4 \mathrm{ml}$ of extraction buffer $(100 \mathrm{mM} \mathrm{NaCl}, 10 \mathrm{mM}$ $\mathrm{MgCl}_{2}, 50 \mathrm{mM}$ Tris- $\mathrm{HCl}$ at $\mathrm{pH} 7.5,0.2 \%$ Triton X-100, $5 \mathrm{mM}$ dithiothreitol) containing EDTA-free protease inhibitor cocktail (Roche Diagnostic, Indianapolis, IN, U.S.A.). After two centrifugations (each $15 \mathrm{~min}$ at $20,000 \times g$ ), the supernatants were immobilized on anti-c-myc M2 affinity gel (Sigma, St. Louis) at $4^{\circ} \mathrm{C}$ overnight. All washing steps were repeated four times in the same extraction buffer. Finally, the beads were taken up in polyacrylamide gel electrophoresis loading buffer and were heated at $100^{\circ} \mathrm{C}$ for $5 \mathrm{~min}$. After centrifugation, the proteins were analyzed by Western blot with monoclonal antibodies against myc and HA tags.

\section{Subcellular localization experiments and confocal microscopy.}

Four-week-old $N$. benthamiana plants were co-infiltrated with the Agrobacterium tumefaciens harboring the plasmid pBA002-eYFP-AtRDR6 and that harboring pCAMBIA1300P6-eCFP. Plants were maintained for 2 days at $25^{\circ} \mathrm{C}(16 \mathrm{~h}$ of light and $8 \mathrm{~h}$ of dark) in an incubator. YFP and CFP were observed under a Zeiss LSM 5 EXCITER confocal laser scanning microscope (Carl Zeiss Microimaging $\mathrm{GmbH}$, Oberkochen, Germany). YFP was excited at $514 \mathrm{~nm}$ and fluorescence emission was collected through a 530-nm long-pass emission filter (LP530). CFP was excited at $433 \mathrm{~nm}$ and fluorescence emission was collected through a 470 to $500 \mathrm{~nm}$ band-pass emission filter (BP470-500).

\section{Virus challenge assay.}

RSV, which belongs to the genus Tenuivirus, was used to challenge the P6 transgenic rice plants. Small brown planthoppers (Laodelphax striatellus), the insect vector of RSV, were cultured as previously described (Zhang et al. 2010). Transgenic and control rice seedlings at the two-leaf stage were exposed to viruliferous $L$. striatellus in an inoculation chamber for $48 \mathrm{~h}$, at an insect to plant ratio of 5:1. After the insects were completely removed from the plants, the rice seedlings were continually grown in an incubator. Plants were harvested at 3 and $9 \mathrm{dpi}$, respectively. The whole plants (except the root) were cut and frozen in liquid nitrogen for isolating RNA. About $1 \mu \mathrm{g}$ of total RNA was reverse-transcribed by SuperScript III reverse transcriptase (Invitrogen), using random hexamers as primers, according to the manufacturer's instructions. To quantify the relative viral RNA transcription level, the $2^{-\Delta \Delta C}$ method was applied with a Bio-Rad CFX96 real-time PCR detection system (Bio-Rad, Hercules, CA, U.S.A.) and the Thunderbird SYBR qPCR Mix (Toyobo, Osaka, Japan). The primers rsv-rt-F GATGCGTTGTCTTACCTGACTGC and rsv-rt-R CA CTATCCCATACCTCGACACCA were used for measuring RSV CP gene expression, and Os-actinF GACTCTGGTGAT GGTGTCAGC and Os-actinR GGCTGGAAGAGGACCTCA
GG were used for assaying the level of Osactin11 expression as an internal standard.

\section{ACKNOWLEDGMENTS}

This work was supported by grants from National Natural Science Foundation of China (number 30570077), Major State Basic Research Development Program of China (973 Program 2011CB100700) and Knowledge Innovation Program of Chinese Academy Sciences (KSCX2EW-N-06-3). We thank D. Baulcombe for N. benthamiana line 16c and PVX vector p2C2S, H.-S. Guo for pSK-intron plasmid, G.-L. Wang for pX-DR plasmid and S. Hamera for language editing,

\section{LITERATURE CITED}

Allen, E., Xie, Z., Gustafson, A. M., and Carrington, J. C. 2005. microRNAdirected phasing during trans-acting siRNA biogenesis in plants. Cell 121:207-221

Axtell, M. J., Jan, C., Rajagopalan, R., and Bartel, D. P. 2006. A two-hit trigger for siRNA biogenesis in plants. Cell 127:565-577.

Baumberger, N., Tsai, C. H., Lie, M., Havecker, E., and Baulcombe, D. C. 2007. The polerovirus silencing suppressor P0 targets ARGONAUTE proteins for degradation. Curr. Biol. 17:1609-1614.

Bisaro, D. M. 2006. Silencing suppression by geminivirus proteins. Virology 344:158-168.

Bortolamiol, D., Pazhouhandeh, M., Marrocco, K., Genschik, P., and Ziegler-Graff, V. 2007. The polerovirus $\mathrm{F}$ box protein P0 targets ARGONAUTE1 to suppress RNA silencing. Curr. Biol. 17:1615-1621.

Brigneti, G., Voinnet, O., Li, W. X., Ji, L. H., Ding, S. W., and Baulcombe, D. C. 1998. Viral pathogenicity determinants are suppressors of transgene silencing in Nicotiana benthamiana. EMBO (Eur. Mol. Biol. Organ.) J. 17:6739-6746.

Burgyán, J., and Havelda, Z. 2011. Viral suppressors of RNA silencing. Trends Plant Sci. 16:265-272.

Carthew, R. W., and Sontheimer, E. J. 2009. Origins and mechanisms of miRNAs and siRNAs. Cell 136:642-655.

Chen, S., Tao, L., Zeng, L., Vega-Sanchez, M. E., Umemura, K., and Wang, G. L. 2006. A highly efficient transient protoplast system for analyzing defence gene expression and protein-protein interactions in rice. Mol. Plant Pathol. 7:417-427.

Chen, S., Songkumarn, P., Liu, J., and Wang, G. L. 2009. A versatile zero background T-vector system for gene cloning and functional genomics. Plant Physiol. 150:1111-1121.

Csorba, T., Pantaleo, V., and Burgyán, J. 2009. RNA silencing: An antiviral mechanism. Adv. Virus Res. 75:35-71.

Diaz-Pendon, J. A., Li, F., Li, W. X., and Ding, S. W. 2007. Suppression of antiviral silencing by Cucumber mosaic virus $2 \mathrm{~b}$ protein in Arabidopsis is associated with drastically reduced accumulation of three classes of viral small interfering RNAs. Plant Cell 19:2053-2063.

Ding, S. W., and Voinnet, O. 2007. Antiviral immunity directed by small RNAs. Cell 130:413-426.

Duan, C. G., Fang, Y. Y., Zhou, B. J., Zhao, J. H., Hou, W. N., Zhu, H., Ding, S. W., and Guo, H. S. 2012. Suppression of Arabidopsis ARGONAUTE1-mediated slicing, transgene-induced RNA silencing, and DNA methylation by distinct domains of the Cucumber mosaic virus 2b protein. Plant Cell 24:259-274.

Dunoyer, P., Schott, G., Himber, C., Meyer, D., Takeda, A., Carrington, J. C., and Voinnet, O. 2010. Small RNA duplexes function as mobile silencing signals between plant cells. Science 328:912-916.

Fahlgren, N., Montgomery, T. A., Howell, M. D., Allen, E., Dvorak, S. K., Alexander, A. L., and Carrington, J. C. 2006. Regulation of AUXIN RESPONSE FACTOR3 by TAS3 ta-siRNA affects developmental timing and patterning in Arabidopsis. Curr. Biol. 16:939-944.

Fang, R. X., Wang, Q., Xu, B. Y., Pang, Z., Zhu, H. T., Mang, K. Q. Gao, D. M., Qin, W. S., and Chua, N. H. 1994. Structure of the nucleocapsid protein gene of rice yellow stunt rhabdovirus. Virology 204:367375.

González, I., Martínez, L., Rakitina, D. V., Lewsey, M. G., Atencio, F. A., Llave, C., Kalinina, N. O., Carr, J. P., Palukaitis, P., and Canto, T. 2010. Cucumber mosaic virus $2 \mathrm{~b}$ protein subcellular targets and interactions: Their significance to RNA silencing suppressor activity. Mol. Plant Microbe Interact. 23:294-303.

Gordon, K. H., and Waterhouse, P. M. 2007. RNAi for insect-proof plants. Nat. Biotechnol. 25:1231-1232.

Guo, H. S., Fei, J. F., Xie, Q., and Chua, N. H. 2003. A chemical-regulated inducible RNAi system in plants. Plant J. 34:383-392.

Haas, G., Azevedo, J., Moissiard, G., Geldreich, A., Himber, C., Bureau, M., Fukuhara, T., Keller, M., and Voinnet, O. 2008. Nuclear import of 
CaMV P6 is required for infection and suppression of the RNA silencing factor DRB4. EMBO (Eur. Mol. Biol. Organ.) J. 27:2102-2112.

Hibino, H. 1996. Biology and epidemiology of rice viruses. Annu. Rev. Phytopathol. 34:249-274.

Hiei, Y., Ohta, S., Komari, T., and Kumashiro, T. 1994. Efficient transformation of rice (Oryza sativa L.) mediated by Agrobacterium and sequence analysis of the boundaries of the T-DNA. Plant J. 6:271-282.

Himber, C., Dunoyer, P., Moissiard, G., Ritzenthaler, C., and Voinnet, O. 2003. Transitivity-dependent and -independent cell-to-cell movement of RNA silencing. EMBO (Eur. Mol. Biol. Organ.) J. 22:4523-4533.

Huang, Y., Zhao, H., Luo, Z., Chen, X., and Fang, R. X. 2003. Novel structure of the genome of Rice yellow stunt virus: Identification of the gene 6-encoded virion protein. J. Gen. Virol. 84:2259-2264.

Huang, Y. W., Geng, Y. F., Ying, X. B., Chen, X. Y., and Fang, R. X. 2005. Identification of a movement protein of rice yellow stunt rhabdovirus. J. Virol. 79:2108-2114.

Jackson, A. O., Dietzgen, R. G., Goodin, M. M., Bragg, J. N., and Deng, M. 2005. Biology of plant rhabdoviruses. Annu. Rev. Phytopathol. 43:623-660

Jefferson, R. 1987. Assaying chimeric genes in plants: The GUS gene fusion system. Plant Mol. Biol. Rep. 5:387-405.

Kumakura, N., Takeda, A., Fujioka, Y., Motose, H., Takano, R., and Watanabe, Y. 2009. SGS3 and RDR6 interact and colocalize in cytoplasmic SGS3/RDR6-bodies. FEBS (Fed. Eur. Biochem. Soc.) Lett. 583:1261-1266.

Liu, B., Chen, Z., Song, X., Liu, C., Cui, X., Zhao, X., Fang, J., Xu, W., Zhang, H., Wang, X., Chu, C., Deng, X., Xue, Y., and Cao, X. 2007. Oryza sativa dicer-like4 reveals a key role for small interfering RNA silencing in plant development. Plant Cell 19:2705-2718.

Luo, Z., Chen, X., Gao, D., and Fang, R. 1998. The gene 4 of rice yellow stunt rhabdovirus encodes the matrix protein. Virus Genes 16:277-280.

Luo, Z. L., and Fang, R. X. 1998. Structure analysis of the rice yellow stunt rhabdovirus glycoprotein gene and its mRNA. Arch. Virol 143:2453-2459.

Melnyk, C. W., Molnar, A., and Baulcombe, D. C. 2011. Intercellular and systemic movement of RNA silencing signals. EMBO (Eur. Mol. Biol. Organ.) J. 30:3553-3563

Meyers, B. C., Axtell, M. J., Bartel, B., Bartel, D. P., Baulcombe, D., Bowman, J. L., Cao, X., Carrington, J. C., Chen, X., Green, P. J., Griffiths-Jones, S., Jacobsen, S. E., Mallory, A. C., Martienssen, R. A. Poethig, R. S., Qi, Y., Vaucheret, H., Voinnet, O., Watanabe, Y., Weigel, D., and Zhu, J. K. 2008. Criteria for annotation of plant MicroRNAs. Plant Cell 20:3186-3190.

Moissiard, G., Parizotto, E. A., Himber, C., and Voinnet, O. 2007. Transitivity in Arabidopsis can be primed, requires the redundant action of the antiviral Dicer-like 4 and Dicer-like 2, and is compromised by viral-encoded suppressor proteins. RNA 13:1268-1278.

Molnar, A., Melnyk, C. W., Bassett, A., Hardcastle, T. J., Dunn, R., and Baulcombe, D. C. 2010. Small silencing RNAs in plants are mobile and direct epigenetic modification in recipient cells. Science 328:872-875.

Montgomery, T. A., Howell, M. D., Cuperus, J. T., Li, D., Hansen, J. E., Alexander, A. L., Chapman, E. J., Fahlgren, N., Allen, E., and Carrington, J. C. 2008. Specificity of ARGONAUTE7-miR390 interaction and dual functionality in TAS3 trans-acting siRNA formation. Cell 133:128-141.

Nagasaki, H., Itoh, J., Hayashi, K., Hibara, K., Satoh-Nagasawa, N., Nosaka, M., Mukouhata, M., Ashikari, M., Kitano, H., Matsuoka, M., Nagato, Y., and Sato, Y. 2007. The small interfering RNA production pathway is required for shoot meristem initiation in rice. Proc. Natl. Acad. Sci. U.S.A. 104:14867-14871.

Pantaleo, V., Szittya, G., and Burgyán, J. 2007. Molecular bases of viral RNA targeting by viral small interfering RNA-programmed RISC. J. Virol. 81:3797-3806.

Peragine, A., Yoshikawa, M., Wu, G., Albrecht, H. L., and Poethig, R. S. 2004. SGS3 and SGS2/SDE1/RDR6 are required for juvenile development and the production of trans-acting siRNAs in Arabidopsis. Genes Dev. 18:2368-2379.

Qi, Y., Zhong, X., Itaya, A., and Ding, B. 2004. Dissecting RNA silencing in protoplasts uncovers novel effects of viral suppressors on the silencing pathway at the cellular level. Nucleic Acids Res. 32:e179.

Qu, F., Ren, T., and Morris, T. J. 2003. The coat protein of Turnip crinkle virus suppresses posttranscriptional gene silencing at an early initiation step. J. Virol. 77:511-522.

Qu, F., and Morris, T. J. 2005. Suppressors of RNA silencing encoded by plant viruses and their role in viral infections. FEBS (Fed. Eur. Biochem. Soc.) Lett. 579:5958-5964.

Qu, F., Ye, X., Hou, G., Sato, S., Clemente, T. E., and Morris, T. J. 2005. RDR6 has a broad-spectrum but temperature-dependent antiviral defense role in Nicotiana benthamiana. J. Virol. 79:15209-15217.

Roth, B. M., Pruss, G. J., and Vance, V. B. 2004. Plant viral suppressors of RNA silencing. Virus Res. 102:97-108.

Schwach, F., Vaistij, F. E., Jones, L., and Baulcombe, D. C. 2005. An RNA-dependent RNA polymerase prevents meristem invasion by potato virus $\mathrm{X}$ and is required for the activity but not the production of a systemic silencing signal. Plant Physiol. 138:1842-1852.

Silhavy, D., Molnár, A., Lucioli, A., Szittya, G., Hornyik, C., Tavazza, M., and Burgyán, J. 2002. A viral protein suppresses RNA silencing and binds silencing-generated, 21- to 25-nucleotide double-stranded RNAs. EMBO (Eur. Mol. Biol. Organ.) J. 21:3070-3080.

Tanno, F., Nakatsu, A., Toriyama, S., and Kojima, M. 2000. Complete nucleotide sequence of Northern cereal mosaic virus and its genome organization. Arch. Virol. 145:1373-1384.

Vanitharani, R., Chellappan, P., and Fauquet, C. M. 2003. Short interfering RNA-mediated interference of gene expression and viral DNA accumulation in cultured plant cells. Proc. Natl. Acad. Sci. U.S.A. 100:9632-9636.

Vaucheret, H. 2005. MicroRNA-dependent trans-acting siRNA production. Sci. STKE 2005:pe43.

Vazquez, F., Vaucheret, H., Rajagopalan, R., Lepers, C., Gasciolli, V., Mallory, A. C., Hilbert, J. L., Bartel, D. P., and Crété, P. 2004. Endogenous trans-acting siRNAs regulate the accumulation of Arabidopsis mRNAs. Mol. Cell 16:69-79.

Walker, P. J., Benmansour, A., Dietzgen, R., Fang, R. X., Jackson, A. O., Kurath, G., Leong, J. C., Nadin-Davies, S., Tesh, R. B., and Tordo, N. 2000. Family Rhabdoviridae. Pages 563-583 in: Virus Taxonomy. Seventh Report of the International Committee on Taxonomy of Viruses. Academic Press, San Diego, CA, U.S.A.

Wang, X. H., Aliyari, R., Li, W. X., Li, H. W., Kim, K., Carthew, R., Atkinson, P., and Ding, S. W. 2006. RNA interference directs innate immunity against viruses in adult Drosophila. Science 312:452-454.

Wu, Q., Wang, X., and Ding, S. W. 2010. Viral suppressors of RNA-based viral immunity: Host targets. Cell Host Microbe 8:12-15.

Yang, S. J., Carter, S. A., Cole, A. B., Cheng, N. H., and Nelson, R. S. 2004. A natural variant of a host RNA-dependent RNA polymerase is associated with increased susceptibility to viruses by Nicotiana benthamiana. Proc. Natl. Acad. Sci. U.S.A. 101:6297-6302.

Yoshikawa, M., Peragine, A., Park, M. Y., and Poethig, R. S. 2005. A pathway for the biogenesis of trans-acting siRNAs in Arabidopsis. Genes Dev. 19:2164-2175.

Zhang, F., Guo, H., Zheng, H., Zhou, T., Zhou, Y., Wang, S., Fang, R., Qian, W., and Chen, X. 2010. Massively parallel pyrosequencing-based transcriptome analyses of small brown planthopper (Laodelphax striatellus), a vector insect transmitting rice stripe virus (RSV). BMC Genomics 11:303.

Zhang, X., Garreton, V., and Chua, N. H. 2005. The AIP2 E3 ligase acts as a novel negative regulator of $\mathrm{ABA}$ signaling by promoting $\mathrm{ABI} 3$ degradation. Genes Dev. 19:1532-1543.

Zhang, X., Yuan, Y. R., Pei, Y., Lin, S. S., Tuschl, T., Patel, D. J., and Chua, N. H. 2006. Cucumber mosaic virus-encoded 2b suppressor inhibits Arabidopsis Argonaute1 cleavage activity to counter plant defense. Genes Dev. 20:3255-3268.

Zhu, H., Chen, X., Luo, Z., Fang, R., and Gao, D. 1997. Nucleotide sequence of the rice yellow stunt rhabdovirus gene 2. Chin. J. Virol. 13:369-375.

Zong, J., Yao, X., Yin, J., Zhang, D., and Ma, H. 2009. Evolution of the RNA-dependent RNA polymerase (RdRP) genes: Duplications and possible losses before and after the divergence of major eukaryotic groups. Gene 447:29-39. 